\title{
Discovery of RRx-001, a Myc and CD47 Downregulating Small Molecule with Tumor Targeted Cytotoxicity and Healthy Tissue Cytoprotective Properties in Clinical Development
}

\author{
Bryan Oronsky ${ }^{1 *}$, XiaoNing Guo ${ }^{2}$, XiaoHui Wang ${ }^{2}$, Pedro Cabrales ${ }^{3}$, David Sher ${ }^{4}$, Lou Cannizzo ${ }^{5}$, \\ Bob Wardle ${ }^{5}$, Nacer Abrouk ${ }^{1}$, Michelle Lybeck ${ }^{1}$, Scott Caroen ${ }^{1}$, Arnold Oronsky ${ }^{6}$, Tony R. Reid ${ }^{1}$ \\ Institutions: \\ 1. EpicentRx Inc., 11099 North Torrey Pines Road, Suite 160, La Jolla, CA 92037, USA \\ 2. SciClone Pharmaceuticals Co., Ltd. 22 Floor, Shanghai Central Plaza, No. 381 Middle Huaihai Road, Huangpu, Shanghai \\ 200020, China \\ 3. Department of Bioengineering, University of California San Diego, 9500 Gilman Drive, La Jolla, CA 92093, USA \\ 4. Department of Radiation Oncology, UT Southwestern Medical Center, 2280 Inwood Road, Dallas, TX 75390, USA \\ 5. Department of Space Systems, Northrop Grumman Corporation, 2980 Fairview Park Drive, Falls Church, VA 22042, USA \\ 6. InterWest Partners, 467 First Street, Suite 201, Los Altos, CA 94022, USA
}

\section{Supporting information:}

\section{RRx-001 (ABDNAZ) HPLC}

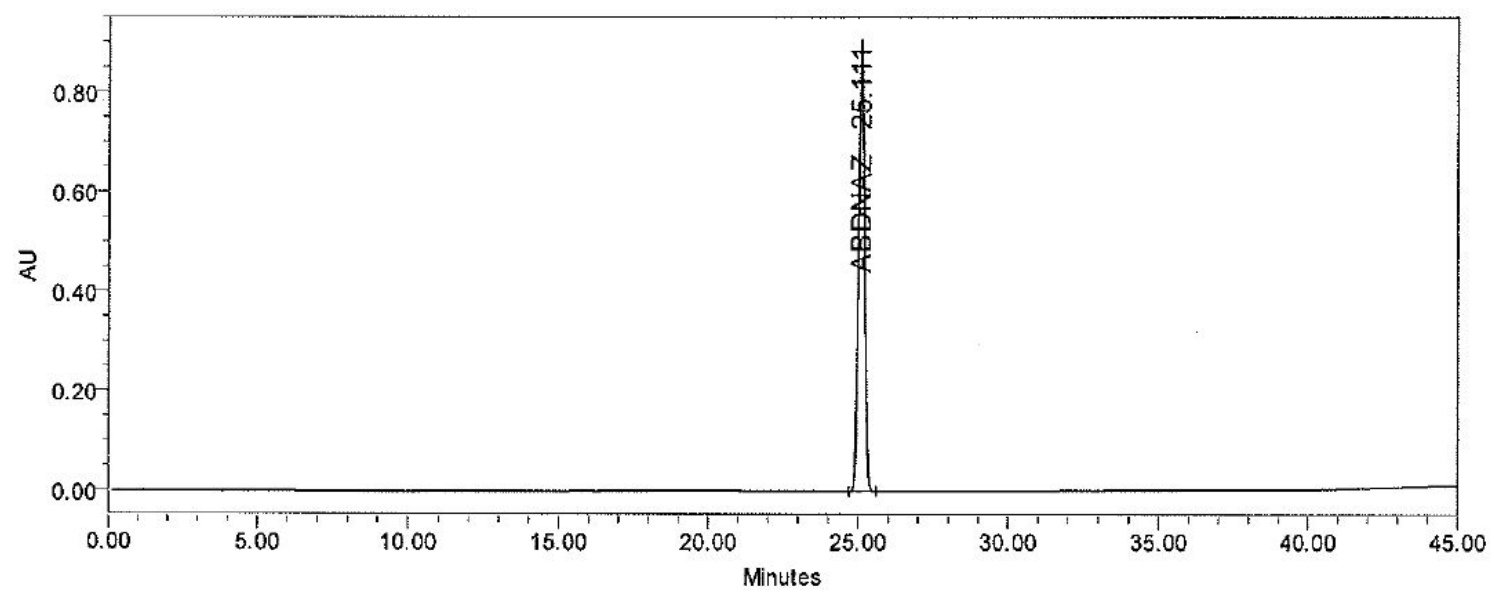

